\title{
Unusual Regioselectivity in the Gold(I)-Catalyzed [3+2] Carbocycloaddition Reaction of Vinyldiazo Compounds and N- Allenamides
}

\author{
Enol López, ${ }^{\text {a,b }}$ Javier González, ${ }^{\mathrm{a}}$ Luis A. López ${ }^{\mathrm{a}, \mathrm{b} *}$
}

a Departamento de Química Orgánica e Inorgánica, Universidad de Oviedo, c/ Julián Clavería, 8, 33006-Oviedo

b Instituto Universitario de Química Organometálica “Enrique Moles”, Universidad de Oviedo, c/ Julián Clavería, 8, 33006-Oviedo

E-mail: lalg@uniovi.es

Received: ((will be filled in by the editorial staff))

Supporting information for this article is available on the WWW under http://dx.doi.org/10.1002/adsc.201\#\#\#\#\#\#.((Please delete if not appropriate))

\begin{abstract}
The reaction of $\mathrm{N}$-allenamides with alkenyldiazo compounds in the presence of gold catalysts provided methylidenecyclopentene derivatives resulting from a formal intermolecular [3+2] carbocyclization, a rare process in the gold chemistry of allenes. The participation of the $C \alpha=C \beta$ of the allenamide represents a very unusual regioselectivity in gold-catalyzed cycloaddition reactions of this type of allenic scaffolds. A stepwise mechanism involving initial activation of the diazo component has been proposed.
\end{abstract}

Keywords: Allenes; Carbenes; [3+2] Cycloaddition; Diazocompounds; Gold

Over the past decades, significant progress has been made toward developing efficient and selective transition metal-catalyzed synthetic methodologies involving allenamides. ${ }^{[1]}$ However, catalytic methods based on the use of gold complexes as catalysts have only recently become available. ${ }^{[2]}$ From a mechanistic proint of view, ${ }^{[3]}$ it is generally accepted that the coordination of the allenamide to gold renders an electrophilic species, which is able to participate in nucleophilic additions and cycloaddition reactions (Scheme 1, a). Specifically, a number of goldcatalyzed carbocycloadditions of allenamide derivatives, including $[2+1],{ }^{[4]}[2+2],{ }^{[5]}$ and $[4+2]^{[6]}$ cycloadditions, have been recently reported. Additionally, the synthesis of some heterocyclic compounds through gold-catalyzed $[3+2]^{[7]}$ and $[2+2+2]^{[8]}$ cycloaddition reactions of allenamide derivatives has been also disclosed. Interestingly, all of the above-mentioned cyclization processes share the characteristic of being highly regioselective, the allene $\mathrm{C} \beta=\mathrm{C} \gamma$ bond being solely involved (Scheme 1, b). a) Accepted mode of activation of allenamides by gold(I) catalysts

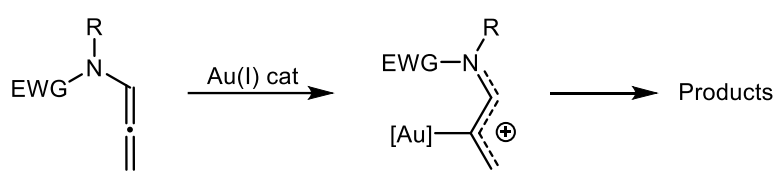

b) Regioselectivity patterns in gold(I)-catalyzed [n+2] cycloadditions

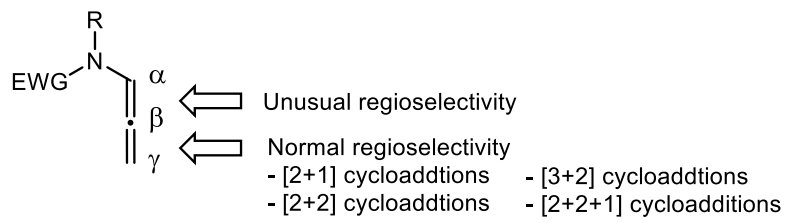

c) A sole example of cyclization involving the $C \alpha-C \beta$ bond of the allenamide<smiles>[R]C#C/C(=C/[R])C([R])=O</smiles>

Scheme 1. a) Activation of allenamides by gold(I) catalysts. b) Normal and unusual regioselectivity in gold (I)-catalyzed [ $\mathrm{n}+2]$ cycloaddition reactions of allenamides. c) A recent (and unique) example of gold (I)-catalyzed cycloaddition of allenamides involving the $\mathrm{C} \alpha=\mathrm{C} \beta$ bond of the allenamide ( $\mathrm{L}=$ chiral ligand $)$.

On the other hand, the transition metal-catalyzed transformations of stabilized vinyldiazo derivatives have received in the last years great attention. In most cases, the so-generated metal vinylcarbene species show a typical carbene reactivity transferring the carbene unit to saturated and unsaturated substrates. ${ }^{[9]}$ Vinylogous reactivity, although less developed, has evolved in the last years as another synthetically useful pathway for metal vinylcarbene intermediates 
generated from vinyldiazo compounds. ${ }^{[10]}$ Surprisingly, despite impressive recent progresses in this field, to the best of our knowledge, the cycloaddition between vinyldiazo derivatives and allene derivatives remains unexplored. In this regard, we realized that the recent introduction of gold complexes as efficient catalysts for the activation of diazo compounds ${ }^{[11]}$ could pave the way for the successful development of a selective cycloaddition of vinyldiazo compounds and allenamides. ${ }^{[12]}$ However, such a metal-catalyzed process could pose some challenges. In particular, regioselectivity issues have to be addressed as both reagents have multiple reaction sites. In the case of the allenic partner, the selectivity problems arise from the presence of two reactive orthogonal double bonds. Regarding the vinyldiazo component, both retention of its diazo function, ${ }^{[13]}$ and decomposition into an electrophilic gold-carbene intermediate can be envisioned. This fact along with the above mentioned dichotomy of the postulated carbene intermediate species (carbene $v s$ vinylogous reactivity) could greatly increase the complexity of the process. On the other hand, a number of non-productive self-coupling processes representing potential competitive pathways should be avoided. ${ }^{[14,15]}$ In the most favourable scenario, the selected catalyst should facilitate the preferential activation of one of the two substrates which, once activated, should react in a selective way with the second component while suppressing the above mentioned side reactions.

Herein, we report the realization of this goal; specifically, we describe the gold-catalyzed [3+2] cycloaddition of allenamides toward vinyldiazo compounds. This process represents not only a rare example of intermolecular gold-catalyzed carbo [3+2] cyclization reaction involving allenamides but also an extremely unusual reactivity pattern in the chemistry of this type of allene derivatives. ${ }^{[16]}$ Notably, the observed participation of the $\mathrm{C} \alpha=\mathrm{C} \beta$ represents an extremely infrequent regioselectivity pattern in goldcatalyzed cyclizations of allenamides. In this regard, a recent report by Zhang et al reporting the gold(I)catalyzed cyclization of 2-(1-alkynyl)-2-alken-1-ones with allenamides through the $\mathrm{C} \alpha=\mathrm{C} \beta$ has prompted us to release our results (Scheme $1, \mathrm{c}){ }^{[17]}$

We initially studied the reaction of benzyl 2diazobut-3-enoate (1a) and N-tosylallenamide $2 \mathbf{a}$ $\left(\mathrm{EWG}=\mathrm{Ts}, \mathrm{R}^{3}=\mathrm{Ph}, \mathrm{R}^{4}=\mathrm{H}\right)$ as model substrates. In accordance with our previous research NHC-based gold(I) complexes in dichloromethane were initially selected as the catalytic systems. To our delight, we found that stirring a mixture of vinyldiazo compound $\mathbf{1 a}$ and N-tosylallenamide $\mathbf{2 a}$ (4 equiv) in the presence of $\operatorname{IPr}(\mathrm{MeCN}) \mathrm{AuSbF}_{6}(10 \mathrm{~mol} \%)$ in dichloromethane at room temperature gave the $[3+2]$ cycloadduct $3 \mathbf{a}$ in $40 \%$ yield after column chromatography (Scheme 2). Very significantly, under these reaction conditions no other regioisomeric products were observable by ${ }^{1} \mathrm{H}-\mathrm{NMR}$ spectroscopy. ${ }^{[18]}$
To our delight, a significant increase in the yield of 3a ( $81 \%$ after chromatographic purification) was achieved when JohnPhosAuNTf 2 was used under otherwise similar conditions (10 $\left.\mathrm{mol} \%, \mathrm{CH}_{2} \mathrm{Cl}_{2}, \mathrm{RT}\right)$. Lowering the catalyst loading to $2,5 \mathrm{~mol} \%$ resulted in longer reaction time (16 h) and a lower yield (46\%). Other gold catalysts tested were found to be less efficient for this transformation (see the Supporting Information for full details on the screening and optimization study).

The structure of compound 3a was ascertained by NMR methods, which clearly demonstrated the participation of the $\mathrm{C} \alpha=\mathrm{C} \beta$ bond of the allenamide.

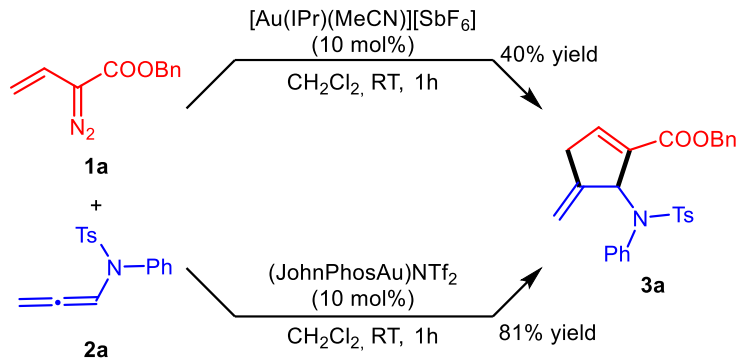

Scheme 2. Gold(I)-catalyzed [3+2] cycloaddition of stabilized vinyldiazo derivatives $\mathbf{1 a}$ and allenamide $\mathbf{2 a}$ : Summary of catalyst optimization.

The reaction was then extended to other combinations of vinyldiazo compounds and allenamides (Scheme $3)$. First, we found that the nature of the ester substituent has little impact on the outcome of the reaction with allenamide $\mathbf{2 a}$. Thus, ethyl substituted vinyldiazo compound $\left(\mathbf{1 b} ; \mathrm{R}^{1}=\mathrm{Et}, \mathrm{R}^{2}=\mathrm{H}\right)$ undergoes the cyclization process affording the corresponding cycloadduct $\mathbf{3 b}$ in $66 \%$ yield. Somewhat lower yield was obtained when using tertbutyl 2-diazobut-3-enoate (1c; $\left.\mathrm{R}^{1}={ }^{t} \mathrm{Bu}, \mathrm{R}^{2}=\mathrm{H}\right)$. Vinyl substitution was tolerated, as demonstrated in the formation of cycloadduct $3 \mathbf{d}$ in $61 \%$ yield when vinyldiazo compound $\mathbf{1 d}\left(\mathrm{R}^{1}=\mathrm{Et}, \mathrm{R}^{2}=\mathrm{Me}\right)$ was subjected to the standard conditions.

Next, we investigated the scope of this goldcatalyzed $[3+2]$ cyclization reaction with regard to the allenamide partner. Indeed, a number of aryl substituted tosylallenamides $\left(\mathrm{EWG}=\mathrm{Ts}, \mathrm{R}^{3}=\right.$ aryl group, $\mathrm{R}^{4}=\mathrm{H}$ ) were compatible with this protocol and those with both electron-rich (allenamides $\mathbf{2} \mathbf{b}$ and 2c; $\quad \mathrm{R}^{3}=4-\mathrm{MeC}_{6} \mathrm{H}_{4}$ and $\mathrm{R}^{3}=3,5-\mathrm{Me}_{2} \mathrm{C}_{6} \mathrm{H}_{3}$, respectively) and electron-deficient aryl groups (allenamide 2d; $\mathrm{R}^{3}=4-\mathrm{FC}_{6} \mathrm{H}_{4}$ ) reacted with vinyldiazo compounds 1a-c to give the expected cycloadducts $\mathbf{3 e - i}$ in moderate yields (42-68\%). A naphthyl-containing cycloadduct 3j was also available from the corresponding tosylallenamide $\mathbf{2 e}$ $\left(\mathrm{R}^{3}=2\right.$-naphthyl, $\left.\mathrm{R}^{4}=\mathrm{H}\right)$. Reactions with N-alkyl substituted tosylallenamides (allenamides $\mathbf{2 f}$ and $\mathbf{2}$; $\mathrm{R}^{3}=\mathrm{Me}$ and $\mathrm{R}^{3}=\mathrm{Bn}$, respectively) also proceeded smoothly to afford the corresponding [3+2] cycloadducts $3 \mathbf{k}-\mathbf{m}$ in moderate yields (34-59\%). 
Variation of the tosyl group was also tolerated as demonstrated the preparation of compound $\mathbf{3 n}$ bearing a 2,4,6-tris(isopropyl)phenyl group. Besides, 1-(1,2-propadienyl)pyrrolidin-2-one (2i) was also a suitable substrate in this gold-catalyzed [3+2] cycloaddition leading to product 3o. Finally, this gold-catalyzed [3+2] cyclization tolerated substitution at the allenyl moiety as demonstrated the formation of product $\mathbf{3 p}$ in $45 \%$ yield from allenamide $2 \mathbf{j}\left(E W G=T s, R^{3}=P h, R^{4}=E t\right)$. Remarkably, this reaction proceeded with total Zselectivity.
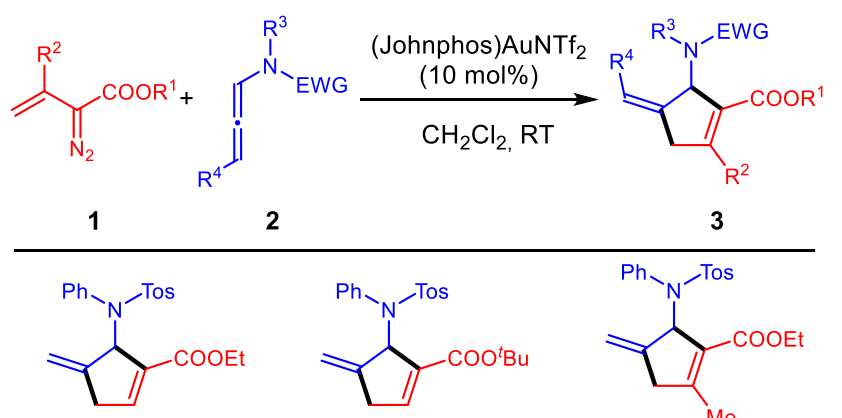

3b $(66 \%)$

$3 c(53 \%)$
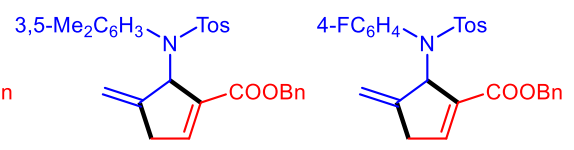

3e $(59 \%)$

$3 f(68 \%)$
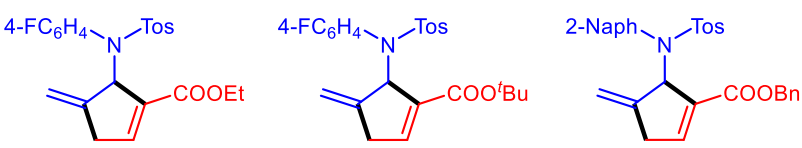

$3 \mathrm{~h}(50 \%)$

$3 \mathbf{i}(47 \%)$

3j (55\%)
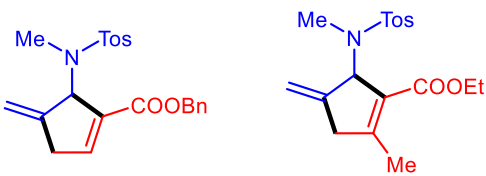

3k $(57 \%)$

$31(34 \%)$

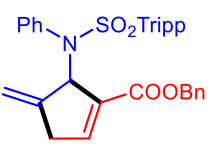

3 n $(58 \%)$

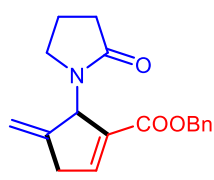

$30(42 \%)$

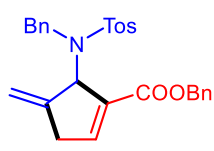

$3 \mathrm{~m}(59 \%)$

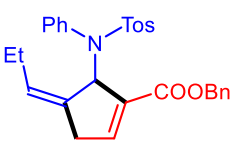

$3 p(45 \%)$

Scheme 3. Gold(I)-catalyzed [3+2] cycloaddition of stabilized vinyldiazo derivatives $\mathbf{1}$ and allenamides 2. Reaction conditions: $1(0.5 \mathrm{mmol}), \mathbf{2}(2.0 \mathrm{mmol})$, (JohnPhosAu)NTf 2 (10 mol\%), $\mathrm{CH}_{2} \mathrm{Cl}_{2}(0.05 \mathrm{M})$, RT. Values in parenthesis are the yields of isolated products. Naph $=$ naphthyl. Tripp $=2,4,6-$ tris(isopropyl)phenyl.
Single-crystal analysis of compound $\mathbf{3 g}$ unambiguously confirmed our initial structural assignment (Figure 1). ${ }^{[19]}$

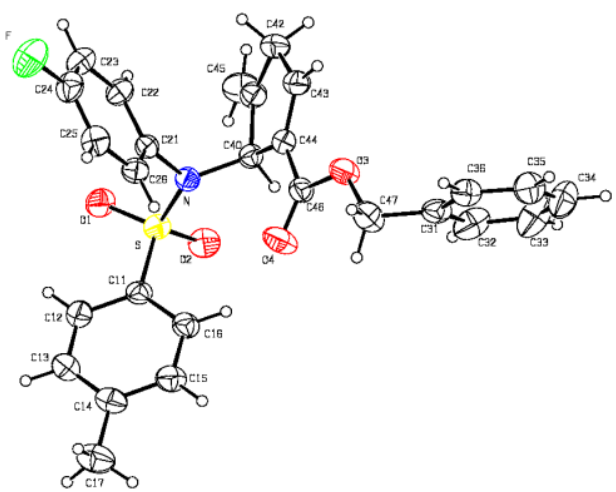

Figure 1. ORTEP view of compound $\mathbf{3 g}$ (ellipsoids at $30 \%$ probability level).

A mechanistic proposal to rationalize the obtained results is depicted in Scheme 4. Although different mechanistic scenarios can be envisioned for the formation of the [3+2]-carbocycloadducts $\mathbf{3}$, the structure of the final products would suggest that it is the activation of the diazo compound rather than of the allene that, very likely, accounts for the cyclization event. As a result, the mechanism would begin with the reaction of the vinyldiazo compound with the gold complex to afford a gold-vinyl carbene intermediate $\mathbf{I}^{\left[{ }^{[20]}\right.}$ In agreement with previous reports, this intermediate would show an enhanced tendency to react through the vinylogous position. Consequently, nucleophilic attack of the central carbon atom of the allenamide to this position would generate intermediate II. ${ }^{[21]}$ This complex would undergo cyclization through attack of the vinyl-gold to the electrophilic iminium atom carbon to release the final product and regenerate the gold-catalyst.

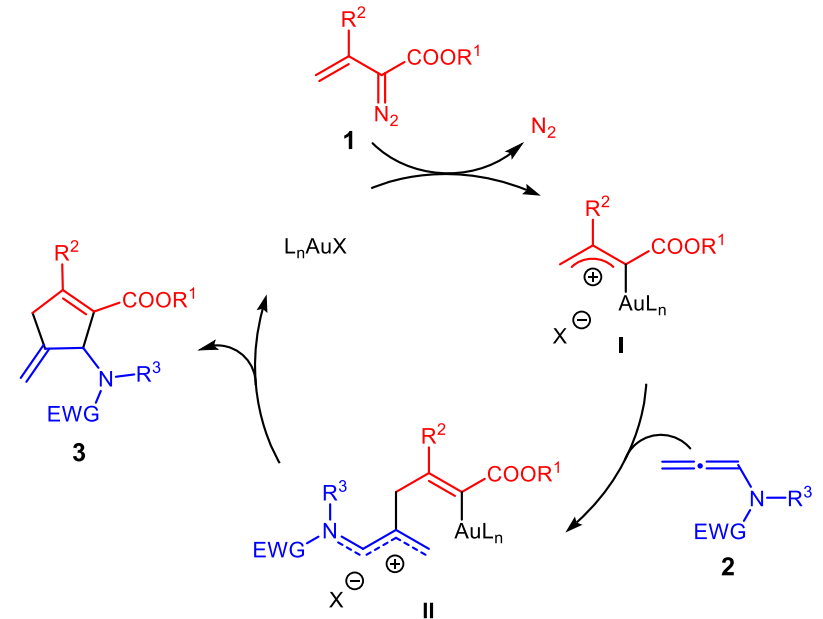

Scheme 4. Proposed mechanism for the synthesis of compounds $\mathbf{3}$ from vinyldiazo compounds $\mathbf{1}$ and $\mathrm{N}$ allenamides 2 . 
Taking into account that previous $[\mathrm{n}+2]$ cyclization reactions involving allenamides are proposed to proceed by activation of the allenic partner by the gold catalyst, the divergent regiochemical outcome observed in our case would be a consequence of the preferential activation of the diazo partner. This proposal is supported by a preliminary computational DFT study (see Supporting Information for details) which shows that the formation of gold(I) carbenetype intermediate I (Scheme 4) is clearly favoured as compared with the activation of the $\mathrm{N}$-allenamide partner. The coordination of the nucleophilic diazo compound to the gold(I) catalytic species leads to an unstable intermediate, which loses a dinitrogen molecule, in a reaction showing a very low activation barrier (the predicted $\Delta \mathrm{G}^{\#}$ values being in the range of 4-6 kcal mol ${ }^{-1}$ ). In addition, the elimination of $\mathrm{N}_{2}$ makes the reaction for the formation of $\operatorname{gold}(\mathrm{I})$ carbene intermediate, quite exothermic.

In summary, we have found new reactivity patterns in gold allene chemistry. Specifically, the reaction of allenamide derivatives with vinyldiazo compounds afforded five-membered rings arising from a [3+2] carbocycloaddition, an uncommon process in gold allene chemistry. Notably, the participation of the $\mathrm{C} \alpha=\mathrm{C} \beta$ represents an extremely infrequent regioselectivity pattern in gold-catalyzed cyclizations of allenamides. These results are fully consistent with a mechanistic pathway involving initial activation of the vinyldiazo partner. Studies to gain further insight into the reaction mechanism and to develop an enantioselective version of the present reaction are ongoing.

\section{Experimental Section}

Representative procedure (3a): JohnPhosAuNTf 2 (39 mg, $0.05 \mathrm{mmol}, 10 \mathrm{~mol} \%$ ) was added to a solution of benzyl 2diazobut-3-enoate (1a; $101 \mathrm{mg}, 0.5 \mathrm{mmol})$ and allenamide 2a $(570 \mathrm{mg}, 2.0 \mathrm{mmol})$ in $\mathrm{CH}_{2} \mathrm{Cl}_{2}(5 \mathrm{~mL})$. The mixture was stirred at room temperature until the disappearance of $1 \mathrm{a}$ (monitored by TLC; 1h). The solvent was removed under reduced pressure and the resulting residue was purified by flash chromatography (silica gel, hexanes/ethyl acetate 10:1) to yield compound 3a $(186 \mathrm{mg}, 81 \%)$. ${ }^{1} \mathrm{H}-$ NMR $\left(\mathrm{CDCl}_{3}, 300 \mathrm{MHz}\right): 2.42(\mathrm{~s}, 3 \mathrm{H}), 2.77(\mathrm{~d}, J=22.8$ $\mathrm{Hz}, 1 \mathrm{H}), 2.96(\mathrm{~d}, J=22.8 \mathrm{~Hz}, 1 \mathrm{H}), 5.03(\mathrm{~d}, J=12.0 \mathrm{~Hz}$, $1 \mathrm{H}), 5.32(\mathrm{~d}, J=12.0 \mathrm{~Hz}, 1 \mathrm{H}), 5.39$ (br s, $1 \mathrm{H}), 5.80$ (br s, $1 \mathrm{H}), 6.19$ (br s, 1H), 6.77 (br s, $1 \mathrm{H}), 6.91$ (d, $J=8.4 \mathrm{~Hz}$, $2 \mathrm{H}), 7.07-7.12(\mathrm{~m}, 2 \mathrm{H}), 7.19-7.37(\mathrm{~m}, 8 \mathrm{H}), 7.66(\mathrm{~d}, J=7.5$ $\mathrm{Hz}, 2 \mathrm{H}) .{ }^{13} \mathrm{C}-\mathrm{NMR}\left(\mathrm{CDCl}_{3}, 75 \mathrm{MHz}\right): 21.6,37.6,66.0$, $66.3,114.4,128.1,128.3,128.5,129.0,132.0,134.3,136.0$, $136.5,138.2,142.8,146.6,147.1,163.2$. HRMS (EI) calculated for $\left[\mathrm{C}_{27} \mathrm{H}_{25} \mathrm{NO}_{4} \mathrm{~S}\right]^{+}\left(\mathrm{M}^{+}\right): 459.1504$, found 459.1507.

\section{Acknowledgements}

Financial support from Ministerio de Economía y Competitividad (MINECO) and Principado de Asturias (grants CTQ2013-41511P, GRUPIN14-013) is gratefully acknowledged. E. L. thanks the Principado de Asturias for a predoctoral grant (Severo Ochoa Program). We thank Prof. J. M. González and Prof. A. Ballesteros for interesting discussions and Dr. J. Borge for his assistance in the collection of the $X$-ray data.

\section{References}

[1] Selected reviews on allene chemistry: a) L.-L. Wei, H. Xiong, R. P. Hsung, Acc. Che, Res. 2003, 36, 773; b) S. Ma, Chem. Rev. 2005, 105, 2829; c) B. Alcaide, P. Almendros, C. Aragoncillo, Chem. Soc. Rev. 2010, 39, 783; d) S. Ma, Acc. Chem. Res. 2009, 42, 1679; e) N. Krause, C. Winter, Chem. Rev. 2011, 111, 1994; f) S. Yu, S. Ma, Angew. Chem. Int. Ed. 2012, 51, 3074.

[2] Recent reviews on gold catalysis: a) R. Dorel, A. M. Echavarren, Chem. Rev. 2015, 115, 9028; b) C. Obradors, A. M. Echavarren, Acc. Chem. Res. 2014, 47, 902; c) A. S. K. Hashmi, Acc. Chem. Res. 2014, 47, 864; d) L. Zhang, Acc. Chem. Res. 2014, 47, 877; e) Y.-M. Wang, A. D. Lackner, F. D. Toste, Acc. Chem. Res. 2014, 47, 889; f) D.-H. Zhang, X.-Y. Tang, M. Shi, Acc. Chem. Res. 2014, 47, 913; g) A. Fürstner, Acc. Chem. Res. 2014, 47, 925; h) B. Alcaide, P. Almendros, Acc. Chem. Res. 2014, 47, 939; i) L. Fensterbank, M. Malacria, Acc. Chem. Res. 2014, 47, 953; j) F. López, J. L. Mascareñas, Beilstein J. Org. Chem. 2011, 1, 1075; k) D. Garayalde, C. Nevado, ACS Catal. 2012, 2, 1462.

[3] For a recent excellent review on the reaction mechanisms of gold-catalyzed transformations of allenes, see: W. Yang, A. S. K. Hashmi, Chem. Soc. Rev. 2014, 43, 2941.

[4] J. Sabbatini, X. Huang, L. F. Veiros, N. Maulide, Chem. Eur. J. 2014, 20, 10636.

[5] Selected intermolecular [2+2] cycloadditions: a) X.X. Li, L.-L. Zhu, W. Zhou, Z. Chen, Org. Lett. 2012 14, 436; b) S. Suárez-Pantiga, C. Hernández-Díaz, M. Piedrafita, E. Rubio, J. M. González, Adv. Synth. Catal. 2012, 354, 1651; c) H. Faustino, P. Bernal, L. Castedo, F. López, J. L. Mascareñas, Adv. Synth. Catal. 2012, 354, 1658; d) S. Suárez-Pantiga, C. Hernández-Díaz, E. Rubio, J. M. González, Angew. Chem. Int. Ed. 2012, 51, 11552; e) P. Bernal-Albert, H. Faustino, A. Gimeno, G. Asensio, J. L. Mascareñas, F. López, Org. Lett. 2014, 16, 6196; f) M. Jia, M. Monari, Q.-Q. Yang, M. Bandini, Chem. Commun. 2015, 51, 2320.

[6] Selected examples of intermolecular [4+2] cycloadditions involving allenamides: a) H. Faustino, F. López, J. Castedo, J. L. Mascareñas, Chem. Sci. 2011, 2, 633; b) J. Francos, F. Grande-Carmona, H. Faustino, J. Iglesias-Sigüenza, E. Díez, I. Alonso, R. Fernández, J. M. Lassaletta, F. López, J. L. Mascareñas, J. Am. Chem. Soc. 2012, 134, 14322; c) V. Pirovano, L. Decataldo, E. Rossi, R. Vicente, Chem. Commun. 2013, 49, 3594; d) Y. Wang, P. Zhang, Y. Liu, F. Xia, J. Zhang, Chem. Sci. 2015, 6, 5564 .

[7] a) W. Zhou, X.-X. Li, G.-H. Li, Y. Wu, Z. Chen, Chem. Commun. 2013, 49, 3552; b) G.-H. Li, W. Zhou, X.-X. Li, Q.-W. Bi, Z. Wang, Z.-G. Zhao, W.X. Hu, Z. Chen, Chem. Commun. 2013, 49, 4770.

[8] H. Faustino, I. Varela, J. L. Mascareñas, F. López, Chem. Sci. 2015, 6, 2903. 
[9] For a selection of relevant recent contributions on the applications of vinyldiazoacetates: a) S. N. Karad, R.S. Liu, Angew. Chem. Int. Ed. 2014, 53, 5444; b) N. S. Y. Loy, A. Singh, X. Xu, C.-M. Park, Angew. Chem. Int. Ed. 2013, 52, 2212; c) X. Xu, P. Y. Zavalij, W. Hu, M. P. Doyle J. Org. Chem. 2013, 78, 1583; d) X. Xu, P. Y. Zavalij, M. P. Doyle, Angew. Chem. Int. Ed. 2012, 51, 9829;

[10] For selected recent examples of vinylogous reactivity of metal vinylcarbene intermediates, see: a) C. Qin, H. M. L. Davies, Org. Lett. 2013, 15, 6152; b) X. Xu, P. Y. Zavalij, M. P. Doyle, Angew. Chem. Int. Ed. 2013, 52, 12664; c) J. H. Hansen, H. M. L. Davies, Chem. Sci. 2011, 2, 457; d) J. Barluenga, G. Lonzi, L. Riesgo, L. A. López, M. Tomás, J. Am. Chem. Soc. 2010, 132, 13200 .

[11] For a seminal contribution on gold-catalyzed carbene transfer from ethyl diazoacetate to unsaturated substrates, see: a) M. R. Fructos, T. R. Belderrain, P. de Frémont, N. M. Scott, S. P. Nolan, M. M. DíazRequejo, P. J. Pérez, Angew. Chem. Int. Ed. 2005, 44, 5284. For some relevant recent examples, see: b) J. F. Briones, H. M. L. Davies, J. Am. Chem. Soc. 2012, 134, 11916; c) Z. Yu, B. Ma, M. Chen, H.-H. Wu, L. Liu, J. Zhang, J. Am. Chem. Soc. 2014, 136, 6904; d) Y. Xi, Y. Su, Z. Yu, B. Dong, E. J. McClain, Y. Lan, X. Shi, Angew. Chem. Int. Ed. 2014, 53, 9817.

[12] For selected gold-catalyzed reactions of stabilized vinyldiazo compounds involving alkenylgold carbene intermediates, see: a) E. López, G. Lonzi, L. A. López, Organometallics, 2014, 33, 5924; b) J. F. Briones, H. M. L. Davies, J. Am. Chem. Soc. 2013, 135, 13314; c) G. Lonzi, L. A. López, Adv. Synth. Catal. 2013, 355, 1948; d) J. Barluenga, G. Lonzi, M. Tomás, L. A. López, Chem. Eur. J. 2013, 19, 1573; e) V. V. Pagar, A. M. Jadhav, R.-S. Liu, J. Am. Chem. Soc. 2011, 133, 20728.

[13] For selected gold-catalyzed reactions of stabilized vinyldiazo compounds that do not involve initial diazo decomposition into alkenylgold carbene intermediates, see: a) A. M. Jadhav, V. V. Pagar, R.-S. Liu, Angew. Chem. Int. Ed. 2012, 51, 11809; b) V. V. Pagar, A. M. Jadhav, R.-S. Liu, J. Org. Chem. 2013, 78, 5711; c) V. V. Pagar, R.-S. Liu, Angew. Chem. Int. Ed. 2015, 54, 4923.

[14] The gold(I)-catalyzed dimerization of vinyldiazo compounds has been recently reported: D. Zhang, G. Xu, D. Ding, C. Zhu, J. Li, J. Sun, Angew. Chem. Int. Ed. 2014, 53, 11070. See also, G. Xu, C. Zhu, W. Gu, J. Li, J. Sun, Angew. Chem. Int. Ed. 2015, 54, 883.

[15] For the gold(I)-catalyzed dimerization of allenamide derivatives, see references [5a-c]. The gold(I)catalyzed allenamide $[2+2+2]$-cyclotrimerization has been recently disclosed: C. Hernández-Díaz, E. Rubio, J. M, González, Eur. J. Org. Chem. 2016, 265.

[16] Some [3+2] cycloaddition reactions of chromium alkenyl(methoxy)carbene complexes with allenamides have been reported, see: J. Barluenga, R. Vicente, L. A. López, M. Tomás, J. Am. Chem. Soc. 2006, 128,7050 .

[17] Y. Wang, P. Zhang, D. Qian, J. Zhang, Angew. Chem. Int. Ed. 2015, 54, 14849.

[18] Along with the [3+2] cycloadduct 3a, products arising from the $[2+2]$-cycloaddition (dimerization) and $[2+2+2]$-cyclotrimerization of the allenamide were also detected in the crude reaction mixture. Side products resulting from the dimerization of the vinyldiazo compound were also identified in minor amounts.

[19] CCDC-1427930 (3g) contains the supplementary crystallographic data for this paper. These data can be obtained free of charge from The Cambridge Crystallographic Data Centre via www.ccdc.cam.ac.uk/data_request/cif.

[20] For an interesting recent discussion on the nature of gold carbenoids, see: Y. Wang, M. E. Muratore, A. M. Echavarren, Chem. Eur. J. 2015, 21, 7332.

[21] The participation of allylic cations in the intramolecular reaction of $\alpha$-oxo gold carbenes, generated in situ from the corresponding alkyne, and allenes has been recently postulated by Liu et al: R. K. Kawade, R.-S. Liu, Org. Lett. 2013, 15, 4094. 


\section{COMMUNICATION}

Unusual Regioselectivity in the Gold(I)-Catalyzed [3+2] Carbocycloaddition Reaction of Vinyldiazo Compounds and N-Allenamides

Adv. Synth. Catal. Year, Volume, Page - Page<smiles>C=CC(=N)OCC=IC=CC</smiles>

(JohnPhos)AuNTf (10 $\mathrm{mol} \%)$ $\mathrm{CH}_{2} \mathrm{Cl}_{2}$, $\mathrm{rt}$ $\mathrm{Cl}_{2}, \mathrm{H}$

Enol López, Javier González, Luis A. López* 